\title{
Evaluation of Antioxidant Activity of Pyrus Pyrifolia Fruit Peel Extracts Using Different Extraction Methods
}

\author{
PRIYESH DWIVEDI* and POONAM PRAKASH
}

Department of Chemistry, Sam Higginbottom Institute of Agricultural Technology \& Sciences, Allahabad-211007, (U.P.) India

priyeshmukul@gmail.com

Received 8 June 2014 / Accepted 29 June 2014

\begin{abstract}
The present study is aimed to evaluate antioxidant activity of Pyrus pyrifolia fruit peel extracts by different extraction methods. The fruit peel extracts of Pyrus pyrifolia were prepared by using soaking and Soxhlet method with acetone, ethyl acetate and chloroform: methanol (4:1) solvents. The antioxidant activity of the extracts were determined by using DPPH (2, 2-Diphenyl-1picrylhydrazyl) method. From the results obtained it becomes clear that Soxhlet method is best in terms of high extraction efficiency and extraction of antioxidant compounds. The extracts of soaking method showed less antioxidant activity than Soxhlet extracts. In Soxhlet extraction, the acetone extracts showed maximum antioxidant activity than ethyl acetate and chloroform: methanol (4:1) extracts. Out of the extracts prepared by soaking method of extraction, the extracts of chloroform: methanol (4:1) showed maximum antioxidant activity. Therefore, the antioxidant potential of fruit peel extracts of Pyrus pyrifolia depends upon the both, the extraction method and the solvent used for extraction.
\end{abstract}

Keywords: Pyrus pyrifolia, Soxhlet, Soaking, antioxidant activity.

\section{Introduction}

For thousands of years natural products have played a very important role in health care and prevention of diseases. The World Health Organization estimates that $80 \%$ of the people in developing countries of the world rely on traditional medicine for their primary health care, and about $85 \%$ of traditional medicine involves the use of plant extracts. This means that about 3.5 to 4 billion people in the world rely on plants as sources of drugs ${ }^{1}$. The family Rosaceae comprises many genera, well known for their therapeutic properties. Pyrus pyrifolia is an important member of family Rosaceae and a pear tree species native to China, Japan, and Korea. The plant Pyrus pyrifolia has a handful traditional medicinal use. Pyrus pyrifolia has been used for years as a traditional medicine for alleviating alcohol hangover ${ }^{2}$. The fruit of Pyrus pyrifolia shows significant antioxidant activity. The pear fruit contains six 
triterpenes including three caffeoyl triterpenes. The compounds containing cafeeoyl acid moiety shows higher antioxidant activity than the other compounds without a caffeic acid moiety $^{3}$. The ethanolic extract of immature pear fruit contains fourteen compounds and their radical scavenging activity is also reported ${ }^{4}$. The plant also has industrial importance. Fruit peels of Pyrus pyrifolia are rich in highly pure beta Arbutin ${ }^{5}$. Beta Arbutin is a whitening agent which is widely used in cosmetic products. Not even at maturity, but the immature fruit of Pyrus pyrifolia also has important medicinal value. The immature fruit of $P$. pyrifolia contains a high amount of Malaxinic acid, which shows antifungal, antibacterial and anticancer activity ${ }^{6}$.

Extraction is the first step to investigate the chemical constituents of the natural material. The application of an adequate extraction method not only guarantees the target ingredients to be extracted, but also avoid the interference of other unnecessary components, and therefore, will also simplify the subsequent separation work. In some cases, one extraction step may yield a pure compound. So, the present study is an attempt to determine the antioxidant activity of Pyrus pyrifolia fruit peel using different extraction method.

\section{Experimental}

The fruit peel extracts of Pyrus pyrifolia were prepared by using cold (soaking) and hot (Soxhlet) methods of extraction.

\section{Preparation of extracts by cold (soaking) method}

The peels of Pyrus pyrifolia fruit was suspended in the solvents inside a conical flask. The conical flasks were shaken intermittently for three days at room temperature ${ }^{7}$.

\section{Preparation of extracts by hot (Soxhlet) method}

The peels of Pyrus pyrifolia fruit was submitted to extraction for 72 hours, using Soxhlet extraction method. The volatile distillate was collected over anhydrous sodium sulphate and refrigerated until time of analysis ${ }^{8}$.

\section{Solvents}

The solvents used for extraction were acetone, ethyl acetate and chloroform: methanol (4:1).

\section{Determination of antioxidant activity}

The free radical scavenging capacity of the fruit peel extracts of Pyrus pyrifolia was determined using DPPH method. The method is based on the reduction of colored solution of DPPH (1, 1-diphenyl-2picryl hydrazyl) in presence of extracts measured at $517 \mathrm{~nm}^{9}$. Different concentrations $(100 \mu \mathrm{g} / \mathrm{mL}, 200 \mu \mathrm{g} / \mathrm{mL}, 300 \mu \mathrm{g} / \mathrm{mL}$ and $400 \mu \mathrm{g} / \mathrm{mL})$ of extracts were prepared. Control sample was prepared containing the same volume without any extract was used as blank. \% scavenging of the DPPH free radical was measured using the following equation. Results are shown in Table and also Figures.

$$
\% \text { Inhibition }=\frac{(A c-A o) \times 100}{A c}
$$

Where Ac is the absorbance of control (blank, without extract) and Ao is the absorbance of sample in the presence of the extract.

\section{Results and Discussion}

In order to determine the antioxidant activity of acetone, ethyl acetate and chloroform: methanol (4:1) extracts of Pyrus pyrifolia fruit peel the DPPH method was followed. 
The odd electron in the DPPH free radical gives a strong absorption maximum at $517 \mathrm{~nm}$ and is purple in color. The extract exhibited antioxidant activity by scavenging DPPH (free radical) when the odd electron of DPPH radical becomes paired with hydrogen from a free radical scavenging antioxidant to form the reduced DPPH-H. The antioxidant activity of extracts was found to be dose dependent. The scavenging activity of ascorbic acid was greater than that of all extracts. Due to its higher percentage inhibition, ascorbic acid was used as standard.

Table 1. Comparison of DPPH free radical scavenging activity of acetone extracts prepared by cold and hot extraction methods

\begin{tabular}{ccccccc}
\hline $\begin{array}{c}\text { Conc } \\
\text { In } \\
\mu \mathrm{g} / \mathrm{mL}\end{array}$ & $\begin{array}{c}\text { Ascorbic } \\
\text { acid }\end{array}$ & $\begin{array}{c}\% \\
\text { Inhibtion }\end{array}$ & $\begin{array}{c}\text { Acetone } \\
\text { (cold) }\end{array}$ & $\begin{array}{c}\% \\
\text { Inhibtion }\end{array}$ & $\begin{array}{c}\text { Acetone } \\
\text { (hot) }\end{array}$ & $\begin{array}{c}\% \\
\text { Inhibtion }\end{array}$ \\
\hline 100 & $0.037 \pm 0.0058$ & 89.83 & $0.366 \pm 0.0113$ & 11.16 & $0.335 \pm 0.0096$ & 13.88 \\
200 & $0.030 \pm 0.0075$ & 91.59 & $0.342 \pm 0.0113$ & 16.99 & $0.267 \pm 0.0243$ & 31.36 \\
300 & $0.030 \pm 0.0097$ & 91.67 & $0.308 \pm 0.0166$ & 25.24 & $0.229 \pm 0.0253$ & 41.13 \\
400 & $0.030 \pm 0.0095$ & 91.76 & $0.287 \pm 0.0134$ & 30.33 & $0.184 \pm 0.0158$ & 52.69 \\
\hline \multicolumn{6}{c}{ Values were expressed as MEAN \pm S.D. $(n=3)$}
\end{tabular}

Table 1 clearly represents that the acetone extracts obtained from cold extraction has less radical scavenging activity than the hot extraction in each concentration. Ascorbic acid (standard) showed highest radical scavenging activity than all the different extracts in different concentration. The Table 2 represents that the ethyl acetate extracts obtained from cold extraction has less radical scavenging activity than obtained from hot extraction in each concentration.

Table 2. Comparison of DPPH free radical scavenging activity of ethyl acetate extracts prepared by cold and hot extraction methods

\begin{tabular}{ccccccc}
\hline $\begin{array}{c}\text { Conc } \\
\text { in } \\
\mu \mathrm{g} / \mathrm{mL}\end{array}$ & $\begin{array}{c}\text { Ascorbic } \\
\text { acid }\end{array}$ & $\begin{array}{c}\% \\
\text { Inhibtion }\end{array}$ & $\begin{array}{c}\text { Ethyl acetate } \\
\text { (cold) }\end{array}$ & $\begin{array}{c}\% \\
\text { Inhibtion }\end{array}$ & $\begin{array}{c}\text { Ethyl acetate } \\
\text { (hot) }\end{array}$ & $\begin{array}{c}\% \\
\text { Inhibtion }\end{array}$ \\
\hline 100 & $0.037 \pm 0.0058$ & 89.83 & $0.399 \pm 0.0160$ & 8.06 & $0.393 \pm 0.0372$ & 11.28 \\
200 & $0.030 \pm 0.0075$ & 91.59 & $0.373 \pm 0.0085$ & 14.05 & $0.333 \pm 0.0344$ & 24.83 \\
300 & $0.030 \pm 0.0097$ & 91.67 & $0.348 \pm 0.0115$ & 19.80 & $0.283 \pm 0.0356$ & 36.11 \\
400 & $0.030 \pm 0.0095$ & 91.76 & $0.325 \pm 0.0115$ & 25.11 & $0.244 \pm 0.0377$ & 44.92 \\
\hline
\end{tabular}

Values were expressed as MEAN \pm S.D. $(n=3)$

Same results in chloroform: methanol (4:1) was obtained as in acetone and ethyl acetate. The Table 3 represents that the chloroform: methanol $(4: 1)$ extracts obtained from cold extraction has less radical scavenging activity than the chloroform: methanol (4:1) extracts obtained from hot extraction in each concentration. Ascorbic acid (standard) showed highest radical scavenging activity than all the different extracts in different concentration.

The results obtained from the above study clearly shows that hot extraction method (Soxhlet) is more efficient than cold method of extraction (Soaking). It can be referred by Rostagno and Prado, according to which applying heat and agitation usually accelerates extraction kinetics by making the diffusion of the solute through the interface of the solid matrix with the solvent easier ${ }^{10}$. There is no single and standard extraction method for obtaining bioactive compound from natural products. It is largely dependent upon plant characteristics and particle size, as the internal diffusion may be the limiting step during extraction, and on extraction and evaporation temperature that affects the quality of final product. The results obtained from cold extraction (Soaking) in all the taken solvents are summarized in following Table 4. 
Table 3. Comparison of DPPH free radical scavenging activity of chloroform: methanol (4:1) extracts

\begin{tabular}{ccccccc}
\hline $\begin{array}{c}\text { Conc } \\
\text { in } \\
\mu \mathrm{g} / \mathrm{mL}\end{array}$ & $\begin{array}{c}\text { Ascorbic } \\
\text { acid }\end{array}$ & $\begin{array}{c}\% \\
\text { Inhibtion }\end{array}$ & $\begin{array}{c}\text { Chloroform: } \\
\text { methanol } \\
(4: 1)(\text { cold) }\end{array}$ & $\begin{array}{c}\% \\
\text { Inhibtion }\end{array}$ & $\begin{array}{c}\text { Chloroform: } \\
\text { methanol } \\
(4: 1)(\text { hot })\end{array}$ & $\begin{array}{c}\% \\
\text { Inhibtion }\end{array}$ \\
\hline 100 & $0.037 \pm 0.0058$ & 89.83 & $0.363 \pm 0.0100$ & 11.46 & $0.350 \pm 0.0120$ & 13.15 \\
200 & $0.030 \pm 0.0075$ & 91.59 & $0.319 \pm 0.0085$ & 22.19 & $0.302 \pm 0.0085$ & 25.06 \\
300 & $0.030 \pm 0.0097$ & 91.67 & $0.271 \pm 0.0330$ & 33.90 & $0.253 \pm 0.0305$ & 37.22 \\
400 & $0.030 \pm 0.0095$ & 91.76 & $0.249 \pm 0.0266$ & 39.26 & $0.217 \pm 0.0080$ & 46.15 \\
\hline
\end{tabular}

Values were expressed as MEAN \pm S.D. $(n=3)$

Table 4. DPPH free radical scavenging activity of all the extracts obtained by cold extraction (soaking)

\begin{tabular}{|c|c|c|c|c|c|c|c|c|}
\hline 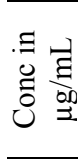 & $\begin{array}{c}\text { Ascorbic } \\
\text { acid }\end{array}$ & 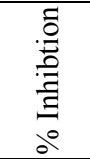 & $\begin{array}{l}\text { Acetone } \\
\text { (cold) }\end{array}$ & 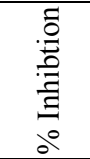 & $\begin{array}{l}\text { Ethyl } \\
\text { acetate } \\
\text { (cold) }\end{array}$ & ○。 胥 & $\begin{array}{l}\text { Chloroform: } \\
\text { Methanol } \\
\text { (4:1) (cold) }\end{array}$ & ○。 \\
\hline 100 & $0.037 \pm 0.0058$ & 89.83 & $0.366 \pm 0.0113$ & 11.16 & $0.399 \pm 0.0160$ & 8.06 & $0.363 \pm 0.0100$ & 11.46 \\
\hline 200 & $0.030 \pm 0.0075$ & 91.59 & $0.342 \pm 0.0113$ & 16.99 & $0.373 \pm 0.0085$ & 14.05 & $0.319 \pm 0.0085$ & 22.19 \\
\hline 300 & $0.030 \pm 0.0097$ & 91.67 & $0.308 \pm 0.0166$ & 25.24 & $0.348=$ & 19.80 & 0.2 & 33.90 \\
\hline 400 & $0.030 \pm 0.0095$ & 91.76 & $0.287 \pm 0.0134$ & 30.33 & $0.325 \pm 0.0115$ & 25.11 & $0.249 \pm 0.0266$ & 39.26 \\
\hline
\end{tabular}

Values were expressed as MEAN \pm S.D. $(\mathrm{n}=3)$

In cold method of extraction chloroform: methanol (4:1) extracts showed better antioxidant activity than acetone and ethyl acetate extracts. At $100 \mu \mathrm{g} / \mathrm{mL}$, chloroform: methanol (4:1) extract showed percentage inhibition $11.46 \%$, which was higher than ethyl acetate $8.06 \%$ and acetone $11.16 \%$. $400 \mu \mathrm{g} / \mathrm{mL}$ showed maximum inhibition in chloroform: methanol (4:1) $39.26 \%$ than the other like ethyl acetate $25.11 \%$, acetone $30.33 \%$. The results obtained from hot extraction (Soxhlet) in all the three solvents are summarized in following Table 5.

Table 5. DPPH free radical scavenging activity of all the extracts prepared by hot extraction method

\begin{tabular}{|c|c|c|c|c|c|c|c|c|}
\hline 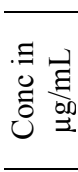 & Asco & 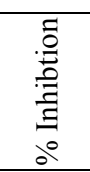 & $\begin{array}{l}\text { Acet } \\
\text { (ho }\end{array}$ & 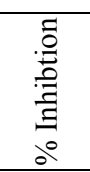 & $\begin{array}{r}\text { Ethyl } \\
\text { (h }\end{array}$ & 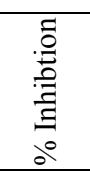 & $\begin{array}{l}\text { Chloroform: } \\
\text { methanol } \\
(4: 1)(\text { hot })\end{array}$ & ㅇํ류류 \\
\hline 10 & & 9.83 & & 3.88 & & 1.28 & & 3.15 \\
\hline 20 & & & & & & 83 & & .06 \\
\hline 300 & 0.00 & 91.67 & & 41.13 & & 36.11 & & 37.22 \\
\hline 400 & $0.030 \pm 0.0095$ & 91.76 & $0.184 \pm 0.0158$ & 52.69 & $0.244 \pm 0.0377$ & 44.92 & $0.217 \pm 0.0080$ & 46.15 \\
\hline
\end{tabular}

Values were expressed as $M E A N \pm S . D$. $(n=3)$

In hot extraction acetone extracts shows the highest percentage activity than ethyl acetate and chloroform: methanol (4:1) extracts. At $100 \mu \mathrm{g} / \mathrm{mL}$, acetone extract showed percentage inhibition $13.88 \%$, which is higher than ethyl acetate $11.28 \%$ and chloroform: methanol (4:1) $13.15 \%$. In the same way $200 \mu \mathrm{g} / \mathrm{mL}, 300 \mu \mathrm{g} / \mathrm{mL}$ and $400 \mu \mathrm{g} / \mathrm{mL}$ acetone extract showed percentage inhibition $31.36 \%, 41.13 \%$ and $52.69 \%$ respectively which is higher than chloroform: methanol (4:1) $25.06 \%, 37.22 \%$ and $46.15 \%$ and ethyl acetate $24.83 \%, 36.11 \%$ and $44.92 \%$ respectively. 
From the results obtained by cold and hot extraction method it is clear that in cold extraction chloroform: methanol (4:1) extracts showed highest antioxidant activity while in the case of hot extraction method the acetone extracts showed highest antioxidant activity. These results can be supported by Sarker et al., which state that in a Soxhlet extraction, it is preferable to use a single solvent simply than a mixture of solvents because one of the solvents in the mixture may distill more rapidly than another ${ }^{11}$. This may lead to a change in the solvent proportions in the extracting chamber.

\section{Conclusion}

From the results of this present study, the two extraction methods namely soaking (cold extraction) and Soxhlet (hot extraction) were compared in the extraction of antioxidant compounds. These results clearly showed that hot extraction is more efficient than cold extraction in the extraction of antioxidant compounds from fruit peels of Pyrus pyrifolia. Further, major drawbacks of cold extraction are long extraction time, labor-intensive procedures, unsatisfactory extraction efficiency and large amount of organic solvents.

An observation of the results obtained from cold (soaking) and hot (soxhlet) extraction methods with all the three solvents viz. acetone, ethyl acetate, chloroform: methanol (4:1) indicate that in cold extraction method the chloroform: methanol (4:1) extracts showed highest potential of antioxidant activity, while in case of hot extraction method, acetone extracts showed highest potential of antioxidant activity. Therefore, the antioxidant potential of fruit peel extracts of Pyrus pyrifolia depends upon both, the extraction method and the solvent used for extraction.

\section{Acknowledgement}

The authors wish to thank many people who made this research possible. Finally, we would like to praise the almighty God.

\section{References}

1. Farnsworth N R and Wilson E O, National Academy Press Washington, 1988, DC 83 -97.

2. Lee S H, Isse T, Kawamoto $\mathrm{T}$, Woo H S, Kim A K, Park J Y and Yang M, Phytotherapy Res., 2012, 26(11), 1753-1758; DOI:10.1002/ptr.4630

3. Cho J Y, Kim C M, Lee H J, Lee S H, Cho J A, Kim W S, Park K H and Moon J H, J Agr Food Chem.., 2013, 61(19), 4563-4569; DOI:10.1021/jf400524b

4. Lee Y G, Cho J Y, Kim C M, Lee S H, Kim W S, Jeon T-II, Park K H and Moon J H, Food Sci Biotechnol., 2013, 22(3), 803-810

5. Cho J Y, Park K Y, Lee K H, Lee H J, Lee S H, Cho J A, Kim W S, Shin S C, Park K $\mathrm{H}$ and Moon J H, Food Sci Biotechnol., 2011, 20(3), 801-807.

6. Lee Y G, Cho J Y, Park J, Lee S H, Kim W S, Park K H and Moon J H, Food Sci Biotechnol., 2013, 22(6), 1539-1545.

7. Odunayo R A, Ibukun E A, Tayo A, Toyin A and Tolu O, AfrJ Tradit Complement Altern Med., 2007, 4(3), 338-344

8. Yang Z N, Yang W, Peng Q, He Q, Feng Y, Luo S and Yu Z, Bangladesh $J$ Pharmacol., 2009, 4(2), 136-143; DOI:10.3329/bjp.v4i2.3232

9. $\quad$ Sonkar R and Mishra R N, Int J Res Pharma Biomed Sci., 2011, 2(2), 579-582.

10. Rostagno M A and Prado J M, Natural Product Extraction: Principle and Application, Royal Society of Chemistry. ISBN: 978-1-84973-606-0, ISSN: 1757-7039.

11. Sarker S D, Latif Z and Gray A I, Natural Product Isolation Second Edition, Humana Press 2005, ISBN: 1-59259-955-9. 